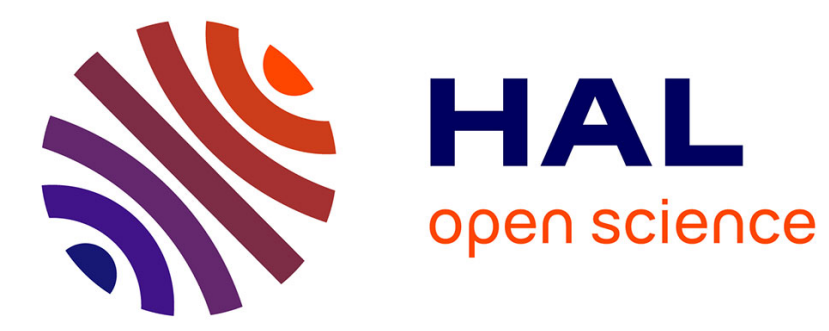

\title{
Role of silicon excess in Er-doped silicon-rich nitride light emitting devices at $1.54 \mu \mathrm{m}$
}

J. M. Ramirez, Sébastien Cueff, Yonder Berencen, Christophe Labbé, B.

Garrido

\section{- To cite this version:}

J. M. Ramirez, Sébastien Cueff, Yonder Berencen, Christophe Labbé, B. Garrido. Role of silicon excess in Er-doped silicon-rich nitride light emitting devices at $1.54 \mu \mathrm{m}$. Journal of Applied Physics, 2014, 116 (8), pp.083103 1-4. 10.1063/1.4893706 . hal-01139287

\section{HAL Id: hal-01139287 \\ https://hal.science/hal-01139287}

Submitted on 3 Apr 2015

HAL is a multi-disciplinary open access archive for the deposit and dissemination of scientific research documents, whether they are published or not. The documents may come from teaching and research institutions in France or abroad, or from public or private research centers.
L'archive ouverte pluridisciplinaire HAL, est destinée au dépôt et à la diffusion de documents scientifiques de niveau recherche, publiés ou non, émanant des établissements d'enseignement et de recherche français ou étrangers, des laboratoires publics ou privés. 


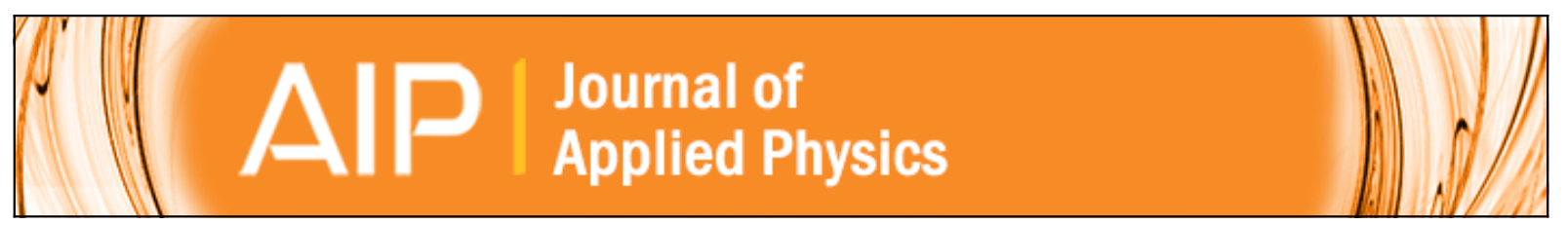

Role of silicon excess in Er-doped silicon-rich nitride light emitting devices at $1.54 \mu \mathrm{m}$

J. M. Ramírez, S. Cueff, Y. Berencén, C. Labbé, and B. Garrido

Citation: Journal of Applied Physics 116, 083103 (2014); doi: 10.1063/1.4893706

View online: http://dx.doi.org/10.1063/1.4893706

View Table of Contents: http://scitation.aip.org/content/aip/journal/jap/116/8?ver=pdfcov

Published by the AIP Publishing

\section{Articles you may be interested in}

Low-voltage driven visible and infrared electroluminescence from light-emitting device based on Er-doped TiO2/p + -Si heterostructure

Appl. Phys. Lett. 100, 031103 (2012); 10.1063/1.3678026

Electroluminescence from Er-doped Si-rich silicon nitride light emitting diodes

Appl. Phys. Lett. 97, 081109 (2010); 10.1063/1.3483771

Electrical conduction and electroluminescence in nanocrystalline silicon-based light emitting devices

J. Appl. Phys. 104, 063103 (2008); 10.1063/1.2977749

Electroluminescence at $1.54 \mu \mathrm{m}$ in Er-doped Si nanocluster-based devices

Appl. Phys. Lett. 81, 3242 (2002); 10.1063/1.1516235

Room-temperature $1.54 \mu \mathrm{m}$ electroluminescence from Er-doped silicon-rich silicon oxide films deposited on $\mathrm{n}+$ Si substrates by magnetron sputtering

J. Appl. Phys. 90, 5835 (2001); 10.1063/1.1413231

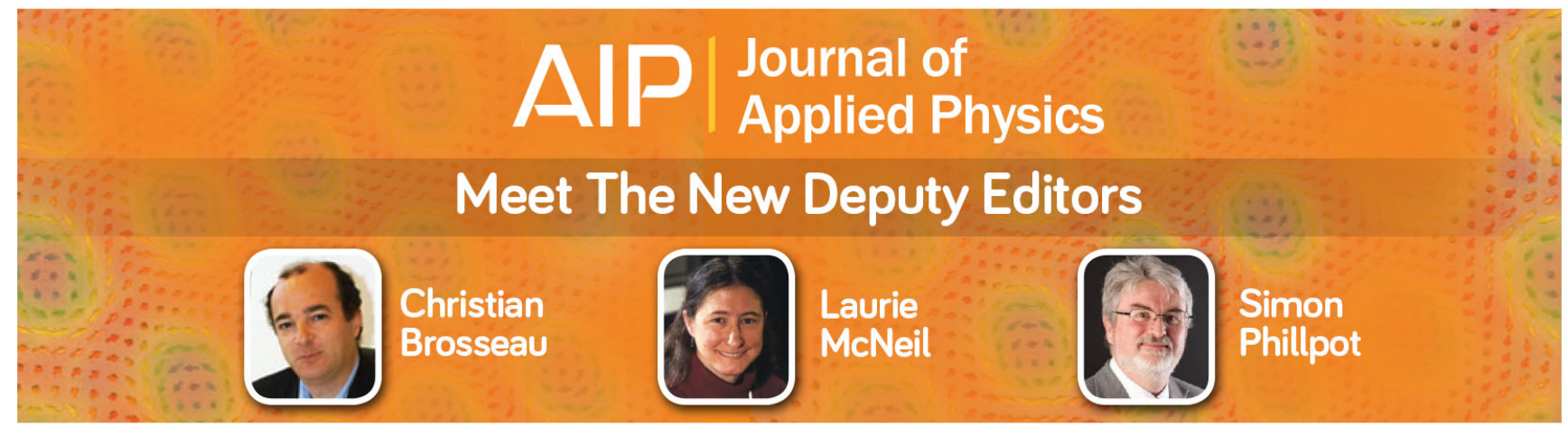




\title{
Role of silicon excess in Er-doped silicon-rich nitride light emitting devices at $1.54 \mu \mathrm{m}$
}

\author{
J. M. Ramírez, ${ }^{1, a)}$ S. Cueff, ${ }^{2}$ Y. Berencén, ${ }^{1}$ C. Labbé, ${ }^{3}$ and B. Garrido ${ }^{1}$ \\ ${ }^{1}$ MIND-IN2UB, Department Electrònica, Universitat de Barcelona, Martí i Franquès 1, Barcelona 08028, \\ Spain \\ ${ }^{2}$ Institut des Nanotechnologies de Lyon, École Centrale de Lyon, Écully 69134, France \\ ${ }^{3}$ Centre de Recherche sur les Ions, les Matériaux et la Photonique (CIMAP), UMR 6252 CNRS/CEA/Ensicaen/ \\ UCBN, Caen 14050, France
}

(Received 23 July 2014; accepted 11 August 2014; published online 25 August 2014)

\begin{abstract}
Erbium-doped silicon-rich nitride electroluminescent thin-films emitting at $1.54 \mu \mathrm{m}$ have been fabricated and integrated within a metal-oxide-semiconductor structure. By gradually varying the stoichiometry of the silicon nitride, we uncover the role of silicon excess on the optoelectronic properties of devices. While the electrical transport is mainly enabled in all cases by Poole-Frenkel conduction, power efficiency and conductivity are strongly altered by the silicon excess content. Specifically, the increase in silicon excess remarkably enhances the conductivity and decreases the charge trapping; however, it also reduces the power efficiency. The main excitation mechanism of $\mathrm{Er}^{3+}$ ions embedded in silicon-rich nitrides is discussed. The optimum $\mathrm{Si}$ excess that balances power efficiency, conductivity, and charge trapping density is found to be close to $16 \%$. C 2014 AIP Publishing LLC. [http://dx.doi.org/10.1063/1.4893706]
\end{abstract}

\section{INTRODUCTION}

Silicon-based integrated photonics have garnered strong interest as a potential technology platform that is able to overcome the limitations of the microelectronics industry. ${ }^{1}$ However, despite the large number of silicon-based photonic components already available, an efficient device emitting at $1.54 \mu \mathrm{m}$ for on-chip light distribution has not been developed yet. Several attempts were accomplished using Er-doped silicon-rich oxides as active material, taking advantage from the superior optoelectronic performance provided by silicon nanoclusters (Si-ncs). ${ }^{2}$ Also in that line, some research groups have suggested using silicon nitride as the primary element in a new CMOS-compatible photonic platform to develop not only passive photonic components but also active devices. ${ }^{3,4}$ In fact, silicon nitride is potentially an ideal host for Er as its band gap enables good electrical injection while minimizing undesirable effects, such as two-photon absorption and energy back transfer. ${ }^{5}$

Nonetheless, despite the promising capabilities offered by Er-doped silicon-rich nitrides (Er-SRN), most research solely focuses on their optical properties. Only a few works are dedicated to study the optoelectronic properties of such materials. ${ }^{5,6}$ As a consequence, the excitation mechanisms of luminescent centers and the correlation with the carrier transport inside Er-SRN films are still not well understood and are often subject of controversy among authors. Efficient Er sensitization from the $\mathrm{SiN}_{\mathrm{x}}$ matrix has been proposed to explain the observed Er electroluminescence (EL) and the high excitation cross-section extracted $\left(\sim 10^{-15} \mathrm{~cm}^{2}\right)$ under Poole-Frenkel conduction. ${ }^{5,7}$ However, higher energy radiative transitions of Er with energy values up to $2.3 \mathrm{eV}$ are often

\footnotetext{
a) Author to whom correspondence should be addressed. Electronic mail: jmramirez@el.ub.edu Tel.: +34 93 4039176. Fax: +34 934021148.
}

reported in erbium-doped nitrides. ${ }^{5,8}$ Such visible Er emission lines are not characteristic features of an energy transfer process between Er and a silicon-based host. ${ }^{9}$ Moreover, other works in which similar host matrices have been studied (such as silicon-rich oxides), suggested impact excitation of hot electrons as the main excitation mechanism of Er ions. ${ }^{10}$ For all this, the study of the optoelectronic properties as well as the excitation mechanisms of $\mathrm{Er}^{3+}$ ions embedded in different silicon nitride hosts is interesting and deserves a thorough investigation.

With this motivation in mind, we show in this work that SRN films are suitable matrices to accommodate a large quantity of electrically excitable $\mathrm{Er}^{3+}$ ions and that the amount of Si excess plays a significant role in the conduction and emission characteristics. This study allows devising a material with optimized composition for maximizing electrical to optical conversion as well as device operation lifetime. For that, different Si excess contents were incorporated during the deposition and used to control the optoelectronic properties of our devices. In particular, the effect of the $\mathrm{Si}$ excess on the main transport mechanism, the charge trapping, and the electroluminescence efficiency is investigated, revealing a direct correlation between the charge trapping, the power efficiency, and the layer conductivity. Finally, such correspondence will be used to provide an optimum $\mathrm{Si}$ excess that yields the best optoelectronic performance of ErSRN light emitting devices.

\section{EXPERIMENTAL DETAILS}

Er-SRN films were deposited on p-type silicon substrates $\langle 100\rangle$ with boron doping of $1 \times 10^{15}$ at. $/ \mathrm{cm}^{3}$ by cosputtering silicon and $\mathrm{Er}_{2} \mathrm{O}_{3}$ targets under an argon plasma flow rate of $10 \mathrm{sccm}$. A variable nitrogen gas flow rate $(0.5$ $\mathrm{sccm}, 0.75 \mathrm{sccm}, 0.85 \mathrm{sccm}$, and $1 \mathrm{sccm}$ ) was introduced in 
the chamber for nitrogen incorporation. Substrate deposition temperature was set to $500^{\circ} \mathrm{C}$. All active layers have a nominal thickness of $50 \mathrm{~nm}$. Later on, a highly n-doped polysilicon layer $100 \mathrm{~nm}$-thick was deposited by low pressure chemical vapor deposition (LPCVD) and used as a semitransparent electrode. Samples were subsequently annealed at $950{ }^{\circ} \mathrm{C}$ for $30 \mathrm{~min}$ in $\mathrm{N}_{2}$ environment to passivate the top electrode and to activate $\mathrm{Er}^{3+}$ ions. The final Si excess was measured by X-ray photoelectron spectroscopy (XPS), obtaining four different values: $12 \%, 16 \%, 20 \%$, and $40 \%$. Time-of-flight secondary ion mass spectrometry (Tof-SIMS) was used to estimate the Er concentration, which was around of $5 \times 10^{20} \mathrm{at} / \mathrm{cm}^{3}$ for all samples. ${ }^{11}$ The bottom contact was defined by covering the wafer backside with a thin aluminum layer. Finally, an aluminum box was deposited on top of the polysilicon electrode, along the device perimeter, to guarantee the voltage homogeneity in the upper electrode. ${ }^{6}$ Electrical characterization was performed using a probe station connected to a semiconductor device analyzer (B1500A). EL was collected from a near-infrared objective and driven to a grating spectrometer coupled to an infrared photomultiplier tube detector (H10330-75). All experiments were performed at room temperature.

\section{RESULTS AND DISCUSSION}

The device cross-section and the polarization schema of devices are presented in Fig. 1. All samples were biased under accumulation regime, i.e., a negative voltage is applied to the top electrode with a voltage ramp of $0.1 \mathrm{~V} / \mathrm{s}$. Fig. 2(a) shows the current density-electric field (J-E) characteristic of Er-SRN films with different Si excess, being the current density $(\mathrm{J})$ the ratio between the injected current and the device area and the electric field (E) the ratio between the applied voltage and the Er-SRN film thickness. Progressive (i.e., from zero to the maximum voltage before the device breakdown) and regressive (i.e., from maximum voltage to zero values) sweeps are displayed together for comparison. An increase in current density by several orders of magnitude and a diminution of the turn-on voltage can be observed when the Si content is increased. This is an expected trend as

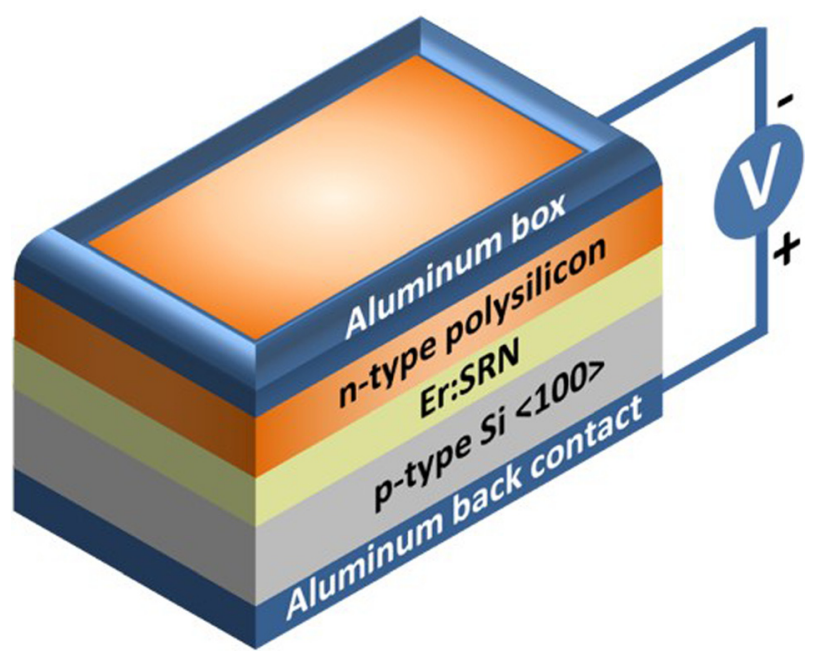

FIG. 1. Device cross-section and polarization schema of devices.
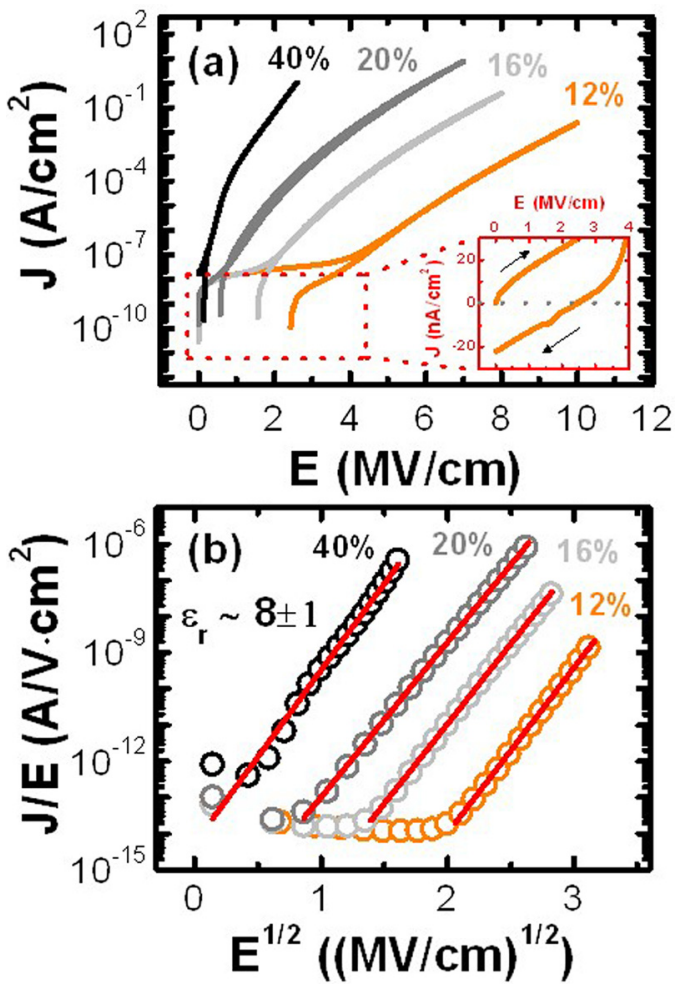

FIG. 2. (a) J(E) characteristic of films with different Si excess. Inset shows a magnified region of a linear (J-E) plot for sample with $12 \%$ of Si excess under low electric field polarization. (b) Poole-Frenkel representation of experimental $\mathrm{J}(\mathrm{E})$ curves.

$\mathrm{Si}$ excess is known to introduce intra-band conductive states within the host either as a consequence of Si-ncs formation or due to the defect generation. ${ }^{5}$ Also, notice that during the regressive sweep, at low electric fields, injected current density changes direction upon certain applied electric field. This effect can be observed in the inset of Fig. 2(a), where injected current density crosses the zero current condition and turns negative even for a positive electric field polarization (i.e., around $2.5 \mathrm{MV} / \mathrm{cm}$ in the inset of Fig. 2(a)). Such a phenomenon indicates that a gradual charge trapping takes place in the film during progressive sweep. This trapping produces an internal electric field that opposes the externally driven polarization until a certain value in the regressive sweep, where both become identical (zero current condition). ${ }^{12}$ From this value on, the further decrease in the external electric field implies a net electric field in the opposite direction. The quantification of the maximum internal electric field $\left(\mathrm{E}_{\mathrm{int}}\right)$ in each sample can be easily calculated from the zero current condition. Thus, a value of $2.5 \mathrm{MV} / \mathrm{cm}$ was found for the sample corresponding to a $\mathrm{Si}$ excess of $12 \%$, $1.5 \mathrm{MV} / \mathrm{cm}$ for the one with $16 \%, 0.6 \mathrm{MV} / \mathrm{cm}$ for the one with $20 \%$ and $0.15 \mathrm{MV} / \mathrm{cm}$ for the sample with $40 \%$. The trapped charge density $\left(\rho_{\text {trapped }}\right)$ at zero current condition can be estimated ${ }^{13}$

$$
\frac{E_{\text {int }}}{t}=\frac{\rho_{\text {trapped }}}{C_{\text {film }}},
$$

where $\mathrm{C}_{\text {film }}(\sim 10-40 \mathrm{pF})$ is the dielectric capacitance of each device measured at low frequency condition $(1 \mathrm{kHz})$ and $t$ is 
the layer thickness. The calculated values of $\rho_{\text {trapped }}$ for Si excess of $12 \%, 16 \%, 20 \%$, and $40 \%$ are found to be $1.1 \mu \mathrm{C} / \mathrm{cm}^{2}, 0.15 \mu \mathrm{C} / \mathrm{cm}^{2}, 0.06 \mu \mathrm{C} / \mathrm{cm}^{2}$, and $0.04 \mu \mathrm{C} / \mathrm{cm}^{2}$, respectively. Notice that $\rho_{\text {trapped }}$ systematically decreases with the Si incorporation. Although the increase in Si excess is often correlated with an increase in charge trapping probability, ${ }^{14}$ it may also be instrumental for the charge trapping release via hopping between $\mathrm{Si}$-ncs and/or neighboring intraband states for a sufficiently high density of $\mathrm{Si}$ excess. Indeed, this is what we observe in our films for the studied $\mathrm{Si}$ excess range (from $12 \%$ up to $40 \%$ ). Therefore, high $\mathrm{Si}$ excess is desirable from the electrical point of view as it promotes the charge transport via intra-band conductive states (conductivity enhancement) and also minimizes fixed charge located at trapping centers.

In order to understand the excitation mechanisms that lead to $\mathrm{Er}^{3+}$ emission, the current transport at high fields has been investigated. All samples have been shown to follow a Poole-Frenkel (P-F) trend in the form of ${ }^{6}$

$$
J \propto E \exp \left(-\frac{E_{A}}{k T}\right) \exp \left(\frac{q}{k T}\left(\frac{q E}{\pi \varepsilon \varepsilon_{0}}\right)^{1 / 2}\right),
$$

where $\mathrm{E}_{\mathrm{A}}$ is the average trap activation energy, $\mathrm{kT}$ is the thermal energy, $\mathrm{q}$ is the elementary charge, and $\varepsilon_{\mathrm{r}}$ and $\varepsilon_{0}$ are the relative and absolute permittivity, respectively. The relative permittivity value can be roughly estimated from the slope of the linear fit when plotting the experimental $\mathrm{J}(\mathrm{E})$ curve in a P-F representation, as in Fig. 2(b). The average $\varepsilon_{\mathrm{r}}$ in our samples is $8 \pm 1$. This value is reasonable as it lies between the relative permittivity of stoichiometric silicon nitride $(\sim 7)$ and pure silicon $(\sim 12)$.

The macroscopic nature of the measured current makes difficult to distinguish between different charge transport mechanisms occurring simultaneously. As a consequence, only the most relevant transport mechanism (in terms of current density) prevails when measuring $\mathrm{J}(\mathrm{E})$ curves (Fig. 2(a)). However, secondary mechanisms, such as hopping or hot carrier injection, cannot be completely discarded in our films. The dominance of thermally-assisted P-F conduction was further corroborated by measuring the $\mathrm{J}(\mathrm{E})$ characteristic at different temperatures up to $573 \mathrm{~K}$ (not shown). The average $\mathrm{E}_{\mathrm{A}}$ can be estimated if a mono-energetic trap distribution is considered. A mean value around $0.3 \mathrm{eV}$ and $0.1 \mathrm{eV}$ for $\mathrm{E}_{\mathrm{A}}$ was obtained under low and high voltage polarization, respectively, in agreement with a previous work where similar films with bulk-limited conduction were studied. ${ }^{15}$ Therefore, current transport takes place mainly along electrically tunable conductive channels under the silicon nitride conduction band (for electrons) and valence band (for holes).

Fig. 3(a) depicts the optical power density at $1.54 \mu \mathrm{m}$ as a function of the injected current density for all devices. A typical EL spectrum at $1.54 \mu \mathrm{m}$ is shown in inset of Fig. 3(a). As can be observed, the incorporation of Si excess provides: (i) lower optical power density and (ii) an effective tuning of the current density onset for EL emission at $1.54 \mu \mathrm{m}\left(\mathrm{J}_{\mathrm{EL}-\mathrm{Th}}\right)$. In particular, a gradual shift of $\mathrm{J}_{\mathrm{EL}-\mathrm{Th}}$ towards higher values takes place when the $\mathrm{Si}$ excess increases. This fact points out a detrimental effect of $\mathrm{Si}$
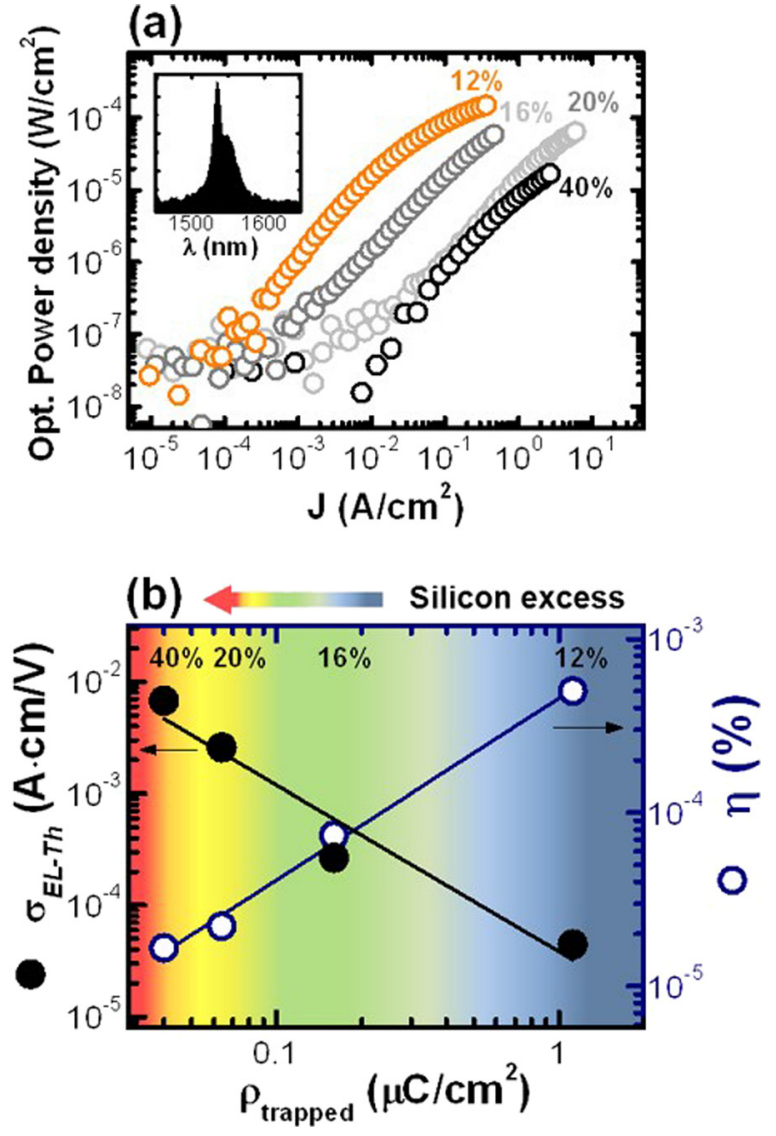

FIG. 3. (a) Total emitted optical power density of Er-SRN with different Si excess as a function of the injected current density. Inset shows an EL spectrum at $1.54 \mu \mathrm{m}$ of device with $12 \%$ of $\mathrm{Si}$ excess taken at $\mathrm{J}=0.02 \mathrm{~A} / \mathrm{cm}^{2}$. (b) Layer conductivity ( $\sigma_{\mathrm{EL}-\mathrm{Th}}$, left axis) and power efficiency $(\eta$, right axis) of devices as a function of the trapped charge density $\left(\rho_{\text {trapped }}\right)$. Values were taken at the EL onset. A color map background displays the evolution of the Si excess with the trapped charge density (from right to left).

excess on the $\mathrm{Er}^{3+}$ excitation, producing a diminution of the generated photons per injected electron and therefore a decrease in the $\mathrm{Er}^{3+}$ excitation efficiency.

Fig. 3(b) summarizes the optoelectronic properties of Er-SRN devices. The power efficiency of devices $(\eta$, defined as the ratio between the emitted optical power and the injected electrical power) and the conductivity of films $\left(\sigma_{\mathrm{EL}-}\right.$ $\mathrm{Th}$, which accounts for the ratio between current density and applied electric field) are plotted as a function of the trapped charge density at zero current condition. As can be observed, devices with higher $\rho_{\text {trapped }}$ (low Si excess) also show higher power efficiency but lower conductivity. On the contrary, devices with low $\rho_{\text {trapped }}$ (high $\mathrm{Si}$ excess) reveal good conductivity but low power efficiency.

Consequently, there is a strong trade-off between the power efficiency and the film conductivity for the studied range of Si excess. Such an opposite trend further confirms the formation of additional "non-radiative" intra-band conduction pathways formed by either defects or Si-ncs (or both) when the Si excess is increased. These intra-band conduction pathways provide an effective channel for the charge transport below the conduction band at the expense of EL efficiency. Furthermore, taking into account that low conductive films also require larger electric fields for a given 
current density (see Fig. 1(a)), one may point out the direct relation between the excitation efficiency and the applied electric field. This fact is of importance as the applied electric field is the one responsible for carrier acceleration in the dielectric conduction band and therefore suggests that the $\mathrm{Er}^{3+}$ excitation in SRN is mainly due to the direct impact excitation of hot carriers, similarly than in other RE-doped silicon oxides. ${ }^{10,12}$ Thus, electrons in SRN would be thermally promoted to the conduction band by Poole-Frenkel ionization mainly, and accelerated by the action of the applied electric field until either they impact with an $\mathrm{Er}^{3+}$ ion (direct impact excitation) or they get trapped by another intra-band state. From this point on, they may either be thermally assisted to the conduction band for a subsequent $\mathrm{Er}^{3+}$ (or intra-band state) interaction again, or hop to the nearest available intra-band state without reaching the conduction band. For the latest, however, the excitation of an $\mathrm{Er}^{3+}$ ion is improbable. Therefore, a non-negligible number of electrically excitable $\mathrm{Er}^{3+}$ ions becomes effectively screened when the $\mathrm{Si}$ excess is incorporated. This interpretation explains: (i) the decrease in $\mathrm{Er}^{3+}$ excitation efficiency when increasing the $\mathrm{Si}$ excess (larger amount of intra-band states and scattering centers); (ii) the direct correlation between the power efficiency and the applied electric field; (iii) the fact that Erdoped silicon nitrides do not show an EL efficiency as high as Er-doped silicon oxides, as bulk-limited dielectric materials (i.e., silicon nitrides) present higher number of intra-band states (and hence higher trapping/de-trapping rate) compared with electrode-limited materials (i.e., silicon oxides). ${ }^{16}$

Another interesting feature that arises when inspecting Fig. 3(b) is the trapped charge density dependence of the device power efficiency. Interestingly, devices with higher trapped charge density also show an enhanced power efficiency performance. Bearing in mind that devices with higher trapped charge density will also be the first ones to reach the charge to breakdown limit, ${ }^{12}$ we foresee larger instability and a diminution of the device operation lifetime in devices with higher power efficiency (and low conductivity) compared with the ones with lower efficiency performance (but higher conductivity). Thus, although the incorporation of Si excess in Er-SRN diminishes the overall EL efficiency, a small Si percentage may be used to further boost the conductivity and the reliability of devices, as well as to strongly diminish the EL onset voltage. Therefore, the crossing point in Fig. 3(b) indicates that the optimum balance between device conductivity and power efficiency is obtained when about $16 \%$ of Si excess is incorporated in the host matrix. This particular layer stoichiometry would provide an optimum optoelectronic performance of Er-SRN electroluminescent thin-films emitting at $1.54 \mu \mathrm{m}$.

\section{CONCLUSION}

In conclusion, the role of $\mathrm{Si}$ excess in the optoelectronic properties of Er-SRN light emitting devices has been investigated, with silicon excess values ranging from $12 \%$ up to $40 \%$. Poole-Frenkel conduction from thermally activated intra-band defects has been shown to be the main charge transport mechanism in all films. Electroluminescent films with low Si content have provided higher power efficiency at the expense of a much reduced layer conductivity and higher trapped charge density. On the contrary, high Si excess has shown to be instrumental to boost the film conductivity and the charge trapping release, although simultaneously displaying lower power efficiency performance. The evolution of the optoelectronic properties with the Si excess has allowed drawing conclusions on the main excitation mechanism of $\mathrm{Er}^{3+}$ ions, which has been found to be direct impact excitation. Finally, we provide an optimum Si excess of $16 \%$, which balances both electrical and optical properties of Er-SRN thin-films emitting at $1.54 \mu \mathrm{m}$.

\section{ACKNOWLEDGMENTS}

This research is supported by the Spanish Ministry of Science and Innovation (TEC2012-38540-C02-01). J.M.R. acknowledges the financial support of Secretariat for Universities and Research of Generalitat de Catalunya through the program FI-DGR 2013. Authors acknowledge the Integrated Nano and Microelectronics Clean Room at IMB-CNM for sample fabrication through the ICTS access program (Project No. ICTS-NGG-235).

${ }^{1}$ A. J. Kenyon, Semicond. Sci. Technol. 20, R65 (2005).

${ }^{2}$ O. Jambois, F. Gourbilleau, A. J. Kenyon, J. Montserrat, R. Rizk, and B. Garrido, Opt. Express 18, 2230 (2010).

${ }^{3}$ D. J. Moss, R. Morandotti, A. L. Gaeta, and M. Lipson, Nat. Photonics 7, 597 (2013).

${ }^{4}$ M. Cazzanelli, F. Bianco, E. Borga, G. Pucke, M. Ghulinyan, E. Degoli, E. Luppi, V. Véniard, S. Ossicini, D. Modotto, S. Wabnitz, R. Pierobon, and L. Pavesi, Nature Mater. 11, 148 (2012).

${ }^{5}$ S. Yerci, R. Li, and L. Dal Negro, Appl. Phys. Lett. 97, 081109 (2010).

${ }^{6}$ S. Cueff, J. M. Ramírez, J. A. Kurvits, Y. Berencén, R. Zia, B. Garrido, R. Rizk, and C. Labbé, Appl. Phys. Lett. 103, 191109 (2013).

${ }^{7}$ Y. Yin, W. Xu, G. Ran, G. Qin, and B. Zhang, Funct. Mater. Lett. 4(03), 255-259 (2011).

${ }^{8}$ Y. Berencén, J. M. Ramírez, and B. Garrido, in Proceedings of the 2013 Spanish Conference on Electron Devices, CDE 2013 (IEEE Xplore, Valladolid, 2013), p. 245.

${ }^{9}$ S. Yerci, R. Li, S. O. Kucheyev, T. V. Buuren, S. N. Basu, and L. Dal Negro, IEEE J. Sel. Top. Quant. Electron. 16(1), 114 (2010).

${ }^{10}$ A. Nazarov, J. M. Sun, W. Skorupa, R. A. Yankov, I. N. Osiyuk, I. P. Tjagulskii, V. S. Lysenko, and T. Gebel, Appl. Phys. Lett. 86, 151914 (2005).

${ }^{11}$ S. Cueff, C. Labbé, L. Khomenkova, O. Jambois, P. Pellegrino, B. Garrido, C. Frilay, and R. Rizk, Mater. Sci. Eng. B 177, 725 (2012).

${ }^{12}$ L. Rebhole and W. Skorupa, Rare-Earth Implanted MOS Devices for Silicon Photonics, Springer Series in Materials Science (Springer, 2010).

${ }^{13}$ S. M. Sze, Physics of Semiconductor Devices, 2nd ed. (Wiley, New York, 1981).

${ }^{14}$ E. Kapetanakis, P. Normand, D. Tsoukalas, K. Beltsios, J. Stoemenos, S. Zhang, and J. van den Berg, Appl. Phys. Lett. 77, 3450 (2000).

${ }^{15}$ Y. Berencén, J. M. Ramírez, O. Jambois, C. Domínguez, J. A. Rodríguez, and B. Garrido, J. Appl. Phys. 112, 033114 (2012).

${ }^{16}$ D. J. DiMaria and J. R. Abernathey, J. Appl. Phys. 60, 1727 (1986). 